\title{
Avance: Una nota preliminar sobre el desempeño de la economía colombiana desde 1888 hasta 2012. Una nueva serie del PIB
}

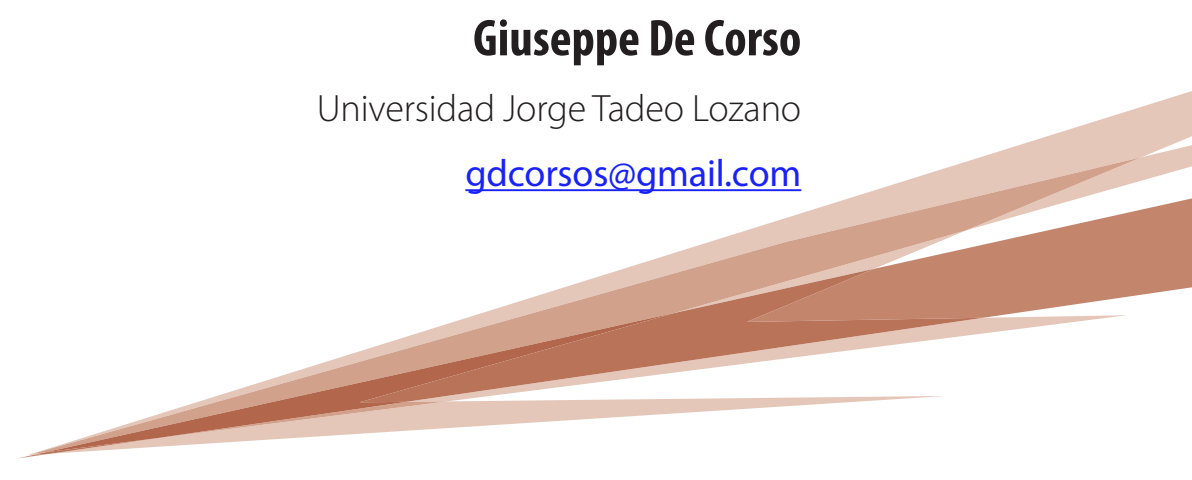

A continuación se presenta un avance de un trabajo en curso, cuyo objetivo es proponer una revisión del comportamiento, en el largo plazo, de por lo menos dos indicadores de la economía colombiana, ${ }^{1}$ el PIB y el PIB per cápita.

\section{Algunas cuestiones sobre el método}

La estimación partió de un cálculo del consumo per cápita de la población, al cual se le añadieron otros agregados económicos, a saber, el gasto fiscal, la formación bruta de capital fijo, y el neto de las exportaciones. Esta serie se empalma con los datos oficiales del DANE, a partir de 1930, y se elabora una sola serie expresada en pesos corrientes, constantes y dólares internacionales de 1990 y 2011 . El resultado es una serie histórica del PIB que abarca desde 1888 hasta 2012.

Para el cálculo del PIB correspondiente al lapso 1888-1929 se empleó el enfoque del gasto: $\mathrm{PIB}=\mathrm{C}+\mathrm{G}+\mathrm{I}+(\mathrm{X}-\mathrm{M})$. El período bajo revisión se concentra, pues, en la etapa que va desde

1 Agradezco al profesor Salomón Kalmanovitz los comentarios y lectura del texto. 
finales del siglo XIX hasta el estallido de la depresión de 1929, y vale la pena resaltar que la estimación de 1888-1905 es inédita. La construcción de la serie, como se mencionó, se inició por el cálculo del posible consumo de la población. Para tal propósito, se elaboraron dos canastas de consumo básico que incluyen alimentos, algunos productos manufacturados como textiles y energía. En total se eligieron 14 productos (azúcar, arroz, cacao, café, carne, harina de trigo [como proxy para pan], maíz, manteca, miel, panela, papa, sal, plátanos y yuca). Las canastas tienen un peso total promedio de 384,60 kilogramos y un valor kilo calórico de alrededor de 2.300 calorías diarias. Los productos alimenticios estratégicos corresponden al 81,90\% del consumo. Es decir, el grueso de la canasta se concibió en torno a los productos de mayor consumo en el mercado interno, y su cantidad en la composición de la canasta se correlacionó con las estadísticas de producción agrícola disponibles en diversas fuentes, especialmente los trabajos de Kalmanovitz sobre la evolución de la agricultura colombiana, teniendo en consideración las posibles pérdidas en el almacenamiento y distribución.

Por otra parte, se añadieron algunas manufacturas y energía como escobas, carbón vegetal, leña y textiles. Tengamos presente que dicha canasta representa el consumo básico por habitante para el país, es decir, incluye los habitantes de todas las edades, por ejemplo, la ingesta de un infante es aproximadamente el $60-70 \%$ de la de un adulto. Es una canasta muy sencilla, pero lo suficientemente representativa del probable consumo medio per cápita de la población en alimentos, energía y manufacturas. La ponderación final que se obtuvo y se empleó como referencia para la construcción del deflactor fue, para la canasta 1 - que abarca aproximadamente desde 1888 hasta la primera década del siglo XX一, de 77,61\% alimentos y un $19,62 \%$ manufacturas/gastos varios, y energía 2,76\%. Mientras que la canasta 2 es $71,32 \%$ alimentos, 20,58 \% manufactura y 8,08 energía y gastos varios, tales como rentas. Como es imposible que todos los colombianos consumieran exactamente las mismas cantidades -esto encarnaría una sociedad de iguales, con un coeficiente de Gini de cero-, multiplicamos entonces la canasta por 0,50 para tomar en consideración las diferencias de ingresos. Este coeficiente de 0,50 expresa, eficazmente, la relación en la distribución del ingreso entre los diversos estratos de población, común en las sociedades agrarias premodernas. En términos generales, en estas sociedades, un $10 \%$ de la población controlaba un $40 \%$ del ingreso nacional.

La inversiones se dedujeron retropolando los datos de GRECO (Grupo de Estudios del Crecimiento Económico Colombiano) hasta 1898 y ajustando los mismos con datos de importaciones extraídos de los trabajos de José Antonio Ocampo, Colombia y la economía mundial 1830-1910, y Santiago Montenegro, El arduo tránsito hacia la modernidad: historia de la industria textil colombiana durante la primera mitad del siglo XX. Igualmente, se usó el manual Export of Manufactures from the United States and Their Distribution by Articles and Countries 1800 to 1906. Department of Commerce and Labor, 1907.

Desde 1888 hasta 1898 usamos el coeficiente venezolano combinado y/o corregido por algunos datos sobre importaciones de bienes de capital del estudio e información de exportaciones de bienes de capital e intermedios norteamericanos hacia Colombia, ya aludido, que representaban, por ejemplo, cerca del $80 \%$ de los bienes de capital para la industria textil. Ahora, es importante subrayar que los datos de inversión para el período 1888-1929 se elaboraron principalmente con la pesquisa efectuada sobre importación de bienes de capital e inversiones extranjeras en áreas de alta concentración de capital foráneo, como ferrocarriles y la expansión de la producción de café. Se examinó, para ajustar las cifras, la estimación de GRE- 
CO en cuanto al comportamiento de la FBKF (Formulación Bruta de Capital Fijo). Se elaboró una nueva serie de población para el cómputo del PIB per cápita, empleándose los censos de los siglos XIX y XX y los datos del Banco Mundial, con algunas modificaciones recomendadas en diversos trabajos de académicos colombianos, específicamente, de María Teresa Ramírez.

Por otro lado, se presentan otras dificultades que es preciso resolver: las series de comercio exterior son algo imprecisas, pero aquí el trabajo mencionado de José Antonio Ocampo ha logrado clarificar el desempeño global del sector externo colombiano entre 1830-1910. Así mismo, las publicaciones del grupo GRECO-Banco de la República y Estadísticas Históricas de Colombia registran series largas del comercio exterior, con algunas lagunas, que se procedió a estimar con base en las exportaciones cafeteras. Para el gasto fiscal, seleccionamos los datos propuestos por Kalmanovitz en el libro coordinado por Adolfo Meisel y María Teresa Ramírez Economía colombiana del siglo XIX, y de Roberto Junguito y Hernán Rincón para el siglo XX. La serie de Kalmanovitz excluye el pago de deuda, pero es muy completa, no presenta vacíos, está expresada en pesos plata, $\mathrm{y}$, de acuerdo con el análisis efectuado, refleja las pautas de la relación gasto público/PIB, que pueden observarse en las primeras décadas del siglo XX.

\section{Resultados parciales}

Existen dos series largas del PIB, una realizada por Dane-Cepal, que se inicia en 1925, y la segunda, del Grupo GRECO del Banco de la Republica, que comprende el período 1905-2000, que contrastamos con la nuestra. A continuación se muestran comparaciones entre las diversas estimaciones utilizando el crecimiento promedio del PIB y PIB per cápita. Para tal propósito, se construyó el cuadro siguiente comparando las diversas series, que no coinciden en cuanto al lapso de tiempo que cubren, pues abarcan tiempos diferentes.

Tasas de crecimiento, en porcentaje, en términos reales, precios de 1975

\begin{tabular}{|c|c|c|c|c|c|c|}
\hline & \multicolumn{2}{|c|}{ De Corso } & \multicolumn{2}{|c|}{ Dane } & \multicolumn{2}{|c|}{ GRECO } \\
\hline & PIB & Pib per cápita & PIB & Pib per cápita & PIB & Pib per cápita \\
\hline 1888-1905 & 1,5 & $-0,3$ & & & & \\
\hline 1905-1929 & 4,0 & 2,0 & nd & nd & 5,8 & 3,7 \\
\hline 1929-1950 & 3,9 & 1,7 & 3,5 & 1,3 & 3,8 & 1,5 \\
\hline 1950-1980 & 5,0 & 2,1 & 5,0 & 2,1 & 5,0 & 2,1 \\
\hline $1980-2000$ & 3,1 & 1,3 & 3,1 & 1,3 & 3,1 & 0,9 \\
\hline 2000-2012 & 4,3 & 3,1 & 4,3 & 3,1 & nd & nd \\
\hline $1905-2000$ & 4,1 & 1,8 & nd & nd & 4,6 & 2,2 \\
\hline $1888-2012$ & 3,9 & 1,7 & nd & nd & nd & nd \\
\hline $1925-2012$ & 4,3 & 2,1 & 4,2 & 2,0 & nd & nd \\
\hline
\end{tabular}

Fuente: cálculos propios, Dane y GRECO; nd, no hay datos. 
Las tasas de crecimiento difieren para determinadas épocas —especialmente en la que va de 1905 a 1929_, entre las que propone GRECO y las nuestras, y esto se debe a diversos factores: la diferencia en el método, series diversas de población y una lectura diferente del efecto de la Primera Guerra Mundial y de la pérdida del Estado Soberano de Panamá, ocurrida en 1903. GRECO deriva el producto de un modelo monetario, donde $Q=M V / P$, o sea el $P I B=$ (Cantidad de dinero*Velocidad de circulación)/nivel de precios, en un país donde todavía no existía un banco central de emisión y donde la penuria monetaria es enorme, lo cual significa que la velocidad de circulación es muy elevada; no puede, por lo tanto, asumirse que es similar a la que se da después de 1923, cuando el Banco de la República comienza a emitir de acuerdo con las necesidades de la economía. Por lo demás, también es pequeño el comercio exterior con relación al valor agregado total. Nuestro cálculo es más directo, pues parte del consumo de la población, y esto tiene una importante ventaja: en una economía preindustrial o premoderna agraria, el $80 \%-90 \%$ del PIB lo representa el consumo de la población, y esa es la fisonomía de la economía colombiana hasta que se inicia con fuerza el proceso de crecimiento económico. Por lo que respecta al valor del PIB per cápita, la estimación nuestra para 1905 es de 833 dólares internacionales de 1990, y la de GRECO, aproximadamente de 600 dólares, diferencia que es resultado de dos enfoques opuestos; el utilizado por nosotros tiene la ventaja de monetizar aquella producción de alimentos orientada al autoconsumo, es decir, no comercializada. Vista en el largo plazo, la estimación que proponemos se mantiene dentro de los parámetros conocidos para la economía colombiana, con un crecimiento del PIB de 4\% y el ingreso por habitante de $2 \%$, ambos en términos reales.

En conclusión, la serie propuesta, y actualmente en revisión final, si bien es una estimación de carácter histórico, con todas las limitaciones que esto implica, consideramos que es la más sólida que se dispone para Colombia, desde el punto de vista metodológico; asimismo, refleja acertadamente los aspectos cualitativos conocidos de la historia económica colombiana, y es, por lo tanto, conveniente como herramienta para estudiar la economía del país, a contraluz de fenómenos sociopolíticos. Por último, y no menos importante, es comparable con otras series regionales y mundiales, pues está expresada en dólares internacionales de 1990 y 2011. 